\title{
COMPLEJIZACIÓN DE UN MODELO DE CULTURA LABORAL MIGRANTE
}

\author{
Oscar Valdés Ambrosio, ${ }^{1}$ María Luisa Quintero Soto,${ }^{2}$ y Cruz García Lirios ${ }^{3}$
}

Resumen: Un modelo complejo alude al establecimiento de las interrelaciones entre factores revisados en la literatura, así como la explicación de fases, dimensiones y aspectos diversos que suponen la dependencia, interdependencia y fusión cultural de migrantes y oriundos en un mercado local. El propósito del trabajo fue elaborar dicho modelo y para ello se realizó un estudio documental con una selección intencional de fuentes indexadas a repositorios nacionales, así como al periodo de publicación y la inclusión de palabras claves de búsqueda. Se advierte una línea de investigación relativa a la identidad como factor constante en las dimensiones, fases e instancias de los flujos migratorios.

Palabras clave: migración, interculturalismo, multiculturalismo, aculturación

\section{COMPLEXIZATION OF A MODEL OF MIGRANT LABOR CULTURE}

Abstract: A complex model alludes to the establishment of the interrelations between factors reviewed in the literature, as well as the explanation of phases, dimensions and diverse aspects that suppose the dependence, interdependence and cultural fusion of migrants and native ones in a local market. The purpose of the work was to elaborate this model and for this a documentary study was carried out with an intentional selection of sources indexed to national repositories, as well as the period of publication and the inclusion of key search words. A line of investigation regarding identity as a constant factor in the dimensions, phases and instances of migratory flows is noticed.

Keywords: migration, interculturalism, multiculturalism, acculturation

\footnotetext{
1 Doctor en Ciencias de la Complejidad; profesor en Facultad de Economía de la UNAM; oscarva@economia.unam.mx.

${ }^{2}$ Doctora en Ciencias Sociales; Profesora e investigadora de Tiempo Completo en UAEMex; S.N.I. II; quinluisa@yahoo.com.mx.

${ }^{3}$ Candidato a doctor por la UNAM; Investigador-docente adscrito a UAEMex; consultor en desarrollo sustentable; cgarcial213@profesor.uaemex.mx.
} 


\section{INTRODUCCIÓN}

La cultura laboral, para los fines del presente trabajo, es aquella instancia y escenario de valores y normas que distinguen a una organización con respecto otras en cuanto al balance entre las demandas externas y los recursos internos.

En ese sentido, la cultura laboral migrante es aquella que supone tres fases; travesía, estancia y retorno, las cuales han sido explicadas desde cinco hipótesis relativas a 1) aculturalismo, 2) biculturalismo, 3) multiculturalismo, 4) interculturalismo y 5) transculturalismo.

Preferentemente, la cultura laboral migrante ha sido vista desde el multilateralismo o las relaciones externas de un país expulsor con respecto a economías receptoras de fuerza laboral y desde el regionalismo o cooperación nacional mediante el subsidio de la industria.

Pues bien, el objetivo del presente estudio es complejizar un modelo para el estudio de la cultura laboral migrante.

Se realizó un estudio documental, transversal y exploratorio con una selección de fuentes indexadas a repositorios nacionales como Latindex y Redalyc, considerando el periodo de publicación de 2010 a 2017, así como la inclusión de palabras claves como "multilateralismo", "regionalismo", “aculturación”, e "multiculturalismo", "interculturalismo".

El análisis del contenido se llevó a cabo mediante la técnica Delphi y se complejizó el modelo a partir de los factores esgrimidos en los marcos teóricos, conceptual y empírico. El proyecto se inscribe en la disciplina de Trabajo Social, área de estudios migratorios, pero incluye conceptos relativos a la psicología de las organizaciones, la salud ocupacional, la sociología del empleo y la economía solidaria.

El proyecto fue financiado por la Universidad Nacional Autónoma de México, Dirección General de Asuntos del Personal Académico, Programa de Apoyo a Proyectos de Investigación e Innovación Tecnológica, registro número IN305516.

\section{TEORÍA DE LA CULTURA LABORAL}

El marco teórico que explica la cultura laboral migrante plantea cuatro niveles: 1) narrativo o relatos evocativos en torno a eventos, actores o situaciones relativas a la organización como un escenario de convivencia; 2) mítico o el de las historias de líderes, sus 
objetivos, tareas y metas que aportaron y coadyuvaron al crecimiento de la organización; 3) rituales o estrategias planificadas como espontáneas en torno a procesos; 4) símbolos o comunicación no verbal orientada a la sincronización y el acoplamiento de esfuerzos.

De este modo, la cultura laboral migratoria establece un balance entre las demandas del exterior y los recursos disponibles en la organización, pero no en un nivel formal sino, más bien flexible que permita el reconocimiento y fortalecimiento de las relaciones laborales y la transferencia de saberes, conocimientos y habilidades.

Es así como los discursos sobre la travesía, la estancia y el retorno permean la cultura laboral migrante, incluyendo sus fases de aculturación, multiculturalismo, interculturalismo y transculturalismo.

En el caso de la aculturación, referente a la asimilación y la adaptación de los migrantes jerarquías, especialidades y motivaciones, es menester considerar que narrativas, misticismo, rituales y símbolos llevan a los flujos migratorios a construir un imaginario laboral que no siempre es cercano a sus expectativas, pero les permite asimilar y adaptarse a los requerimientos del mercado local. En ese sentido, los migrantes son reconocidos como trabajadores más que como líderes de los grupos y equipos (García et al., 2014).

Respecto al multiculturalismo, entendido como un sistema de gestión del conocimiento a partir de la tolerancia de saberes externos a un mercado local, es posible observar que predominan narrativas sobre la calidad de los procesos, misticismo en cuanto a las técnicas y especialidades de los procesos, rituales en torno a habilidades laborales y símbolos de estatus laboral por un empleo más remunerado que el del lugar de origen (Carreón et al., 2017).

En cuanto al interculturalismo se alude al diálogo de saberes entre oriundos y migrantes, narrativas de acoplamiento, misticismo relativo a los resultados esperados, rituales de acercamiento entre los grupos y símbolos de ventajas competitivas al momento de atribuir a un grupo más fuerza laboral o especialidad.

Por último, en el caso del transculturalismo que refiere a la fusión y emergencia de un híbrido laboral que recupera lo mejor de los migrantes y oriundos es posible ver que sus narrativas aluden a aprendizajes al llevar a cabo una tarea, misticismo por la ruptura de una habilidad y adopción de otra técnica, rituales de combinaciones entre las técnicas heredadas 
y aprendidas, así como nuevos símbolos de identidad e innovación al momento de llevar a cabo una función (Carreón et al., 2016).

\section{ESTUDIOS DE LA CULTURA LABORAL MIGRANTE}

El tridente de oportunidades, capacidades y desarrollo encuentra sus fundamentos en marcos teóricos y conceptuales, así como en estudios que el presente trabajo revisó con la finalidad de establecer cuatro ejes de discusión: 1) el primero es relativo a la socialización de comunidades migrantes con respecto a culturas residentes, 2) el segundo supuesto alusivo a la asimilación del mercado laboral, 3) adaptación a la exclusión social promovida por instituciones y grupos residentes y 4) selección de capital humano con base en capacidades que permitan la innovación del mercado laboral.

La revisión permitió discutir los cuatro supuestos para anticipar escenarios de desarrollo humano.

De este modo, fue posible formular una quinta hipótesis en torno a la cual la migración ha sido asociada a la seguridad pública y la economía local como factores preponderantes de desestabilización social.

La migración ha sido abordada desde cuatro hipótesis que orientaron la discusión del estado del conocimiento en referencia al Desarrollo Humano.

La primera hipótesis estriba en que la migración es un fenómeno de socialización con culturas residentes.

El resultado de este proceso es conocido como multiculturalidad y consiste en una estructura jurídica de derechos civiles ante la gobernanza de los recursos comunes que son materializados en servicios públicos.

En este sentido, el desarrollo está confinado a los acuerdos inter y transculturales que establezcan la equidad entre los grupos implicados (García et al., 2015).

Empero, la multiculturalidad reduce a su mínima expresión a las culturas de pueblos originarios puesto que la gobernanza de los recursos está imbrica en la diseminación del capital natural que para las comunidades es concebido como patrimonio local. 
Incluso, los servicios públicos obedecen a principios antropocéntricos en los que la mano de obra migrante es el instrumento idóneo para el establecimiento de alianzas estratégicas entre trasnacionales y micros, pequeñas y medianas empresas.

Es por ello que la segunda hipótesis explicativa de la migración plantea que los flujos económicos determinan los flujos migratorios y ello supone que la mano de obra migrante construya un estilo de vida resiliente.

En efecto, los migrantes son analizados desde su grado de asimilación en relación con el mercado laboral (Carreón et al., 2015).

Sin embargo, la asimilación al mercado laboral por parte de los migrantes sugiere que estos desarrollan capacidades con base en oportunidades que su país de origen les ha cancelado.

Una disminución de las libertades de elección produce mayores capacidades laborales que garanticen la inserción de los migrantes al mercado laboral, pero un aumento de las oportunidades denota un mayor flujo de migrantes y con ello la diversificación de capacidades es abaratada por el exceso de oferta (García et al., 2014).

Más bien, según lo plantea la tercera hipótesis, los migrantes se ven expuestos a una dinámica de escasez de oportunidades que los lleva a desarrollar redes colaborativas a fin de adaptar su cultura a los cambios del mercado laboral.

Este supuesto complementa la cuarta hipótesis en torno a la cual el país receptor de migrantes selecciona talentos y prospectos.

Si la migración es sinónimo de emprendimiento, entonces quienes se desplazan de un lugar a otro no sólo cuentan con las capacidades suficientes para su inserción en el mercado laboral, además son un grupo selecto e innovador de los procesos productos del país receptor.

Las cuatro hipótesis de socialización, asimilación adaptación y selección explican los flujos migratorios en función de la oferta y demanda del mercado laboral.

Cada uno de los cuatro supuestos plantea que el desarrollo humano es posible sólo en aquellos países en los que la oferta laboral, los recursos naturales y los servicios públicos concurren en un marco jurídico de gobierno en red.

En este escenario, la multiculturalidad y la equidad son factores preponderantes que facilitan la concatenación de los flujos económicos, migratorios y laborales (García et al., 2013). 
No obstante, el desarrollo humano también incluye políticas y programas públicos que posibiliten el desarrollo de las generaciones futuras.

Precisamente, las implicaciones de la migración en relación con el desarrollo humano para anticipar un probable escenario de sustentabilidad de los recursos naturales a partir de la gobernanza de servicios municipales y el establecimiento de una agenda pública.

La regulación laboral concibe al trabajo como un escenario de relaciones en los que individuos, demandas y recursos están interrelacionados de tal modo que tienden al desequilibrio ya que las capacidades individuales a menudo son rebasadas por la tecnología, o bien, las demandas no siguen una lógica de desarrollo tecnológico o de formación profesional.

Es por ello que, en la práctica laboral, los individuos ajustan sus capacidades a la escasez de recursos mientras observan el aumento de demandas (Carreón et al., 2014).

Al ser considerada un sistema, una organización es un escenario de desequilibrios y conflictos que llevan a los individuos y a los grupos a buscar mecanismos de balance.

Ante la ausencia de recursos, los individuos dan respuesta a las demandas con ideas creativas o procesos innovadores.

Sin embargo, en un contexto de competitividad, la falta de tecnología supone la intensificación de esfuerzos y por ende la disminución de la calidad de los procesos.

La gestión del conocimiento se cierne sobre aquellos grupos que logran establecer un equilibrio.

Para lograr alcanzar las metas y los objetivos establecidos, las organizaciones suplen la escasez de recursos con relaciones laborales autónomas, confianza, compromiso y motivación.

Los estudios seleccionados para ser conceptualizados por las teorías esgrimidas han encontrado diferencias temporales en cuanto a recursos, establecimiento de la inmigración como tema central de la agenda pública y justificación del autoritarismo político del país receptor, la concentración de migrantes en zonas turísticas, la expulsión mayoritaria de migrantes mexicanos a los Estados Unidos, la adaptación de migrantes al sistema de planificación familiar, el establecimiento de diferencias entre migrantes y residentes con 
respecto a marginación, segregación, asimilación e integración, el auto-concepto del migrante mexicano para con la cultura española, la asociación entre violencia, depresión y autoeficacia y diferencias entre hombres y mujeres respecto a la socialización con la cultura del país que los recibió (Carreón et al., 2016).

Los objetos de estudio esgrimidos se concentran en: 1) pobreza, inmigración, marginación, segregación, violencia y depresión.

Se trata de un círculo vicioso en el que el estrés acumulado indica una desestabilización social que repercute en la dinámica de las organizaciones, grupos e individuos tanto en los países expulsores como en los países receptores de migrantes.

El primer caso explica la migración y el segundo el retorno del migrante; 2) familia, integración, socialización, auto concepto, y auto eficacia.

Tal proceso es un circulo virtuoso en el que la satisfacción laboral está latente y es determinada desde la dinámica familiar hasta por las capacidades individuales pasando por las demandas, recursos organizacionales y cultura laboral.

En estos temas las percepciones de los actores están presentes ya que es la apreciación de la pobreza la que impulsa a los migrantes a buscar empleo en países en los que se les atribuyen mayores y mejores oportunidades de empleo, integración y auto eficacia aunque también se construyen escenarios de inmigración, marginación, segregación, violencia y depresión por el costo de oportunidad que supone abandonar una familia, o bien, la travesía por la que los migrantes atraviesan antes de establecerse laboralmente.

De este modo los estudios relativos a la migración en el ámbito laboral pueden ser esquematizados desde los objetos de estudio y los hallazgos en referencia a percepciones y comportamientos.

El estado del conocimiento, en su trayectoria negativa de factores inherentes a la migración inicia con la percepción de encuadre que explicaría la percepción de pobreza asociada a la inmigración que supone la inserción en un país receptor.

Enseguida, la marginación o segregación esperada al no contar con documentación o especialidad técnica que suponga un empleo mejor remunerado.

Una vez inserto en una organización, la violencia y depresión serían otros aspectos percibidos por los migrantes al momento de interactuar con grupos xenofóbicos (García et al., 2013). 
En su trayectoria positiva, la migración sería impulsada por redes familiares que no sólo integran al migrante a un empleo, sino socializan sus valores, conocimientos y habilidades a fin de incrementar o reducir el auto concepto del grupo para enfocar las capacidades en una actividad remunerada compartida por las redes de apoyo.

Ambas trayectorias pueden ser desglosadas en hipótesis de relaciones de dependencia entre las percepciones aludidas con la finalidad de explicar la variabilidad que supone la búsqueda de empleo.

Los ejes teóricos y conceptuales desde los que es posible discutir cuatro hipótesis explican el fenómeno de la migración con un flujo laboral que determina el desarrollo humano.

En relación con las cuatro hipótesis relativas a la selección, asimilación, adaptación y selección como ejes centrales del desarrollo local sustentable, teórica y conceptualmente los cuatro supuestos explican la inserción laboral de migrantes al mercado laboral.

Sin embargo, teorías y estudios que explican la exclusión social de los migrantes son percibidos como amenazas a la estabilidad laboral y la seguridad pública del país que los acogió.

La migración es un tema idóneo para la difusión que los medios de comunicación construyen para influir en sus audiencias. Siguiendo los presupuestos de los referentes teóricos, la hipótesis de socialización está condicionada por la incidencia a largo plazo de la información diseminada por la televisión.

A diferencia de la radio, prensa o Internet, la televisión construye imágenes que transforman la seguridad pública en percepciones de inseguridad.

Mientras tanto, la migración es difundida como un tema crítico de la agenda nacional y con ello su debate público aproxima a las audiencias a una postura en contra o a favor de la inserción laboral de trabajadores externos.

O bien, la migración es asociada con otros procesos por parte de los noticieros. Ello supone un conjunto de atributos que los espectadores terminan vinculando con alguna problemática local (Carreón et al., 2017). 
Es así como el cultivo, mediatización y encuadre son tres procesos que ahondan en la hipótesis de socialización, pero también explican la asimilación de capacidades en el mercado laboral, la adaptación a los estilos de vida locales o la selección de talentos.

Precisamente, las capacidades laborales de los migrantes explican la asimilación, adaptación y selección de los mismos porque son considerados como talentos ya no por su Resiliencia, sino por sus habilidades y conocimientos adecuados a la flexibilización del mercado laboral.

No obstante, las capacidades de los migrantes están expuestas a sistemas de exclusión y marginalidad que hacen vulnerables a sus redes colaborativas.

La migración laboral en referencia al desarrollo humano supone:

1) la inserción al mercado laboral; oportunidades, demandas, recursos y capacidades que han sido teorizadas, conceptualizadas y observadas con la finalidad de anticipar escenarios futuros de relaciones entre autoridades y ciudadanos;

2) la demostración de diferencias significativas por sexo, edad, ingreso y educación entre grupos residentes con respecto a comunidades migrantes;

3) redes colaborativas que explican cuatro hipótesis relativas a la socialización, asimilación, adaptación y selección;

4) vulneración, marginación y exclusión con respecto a grupos residentes que se perciben amenazados por las demandas y recursos que el mercado laboral impone;

5) el cultivo, mediatización y encuadre de información temas y atributos que determinan el traslado y estancia de migrantes en países receptores, así como el retorno y la reinserción de ex migrantes en países expulsores (García et al., 2015). 


\section{MODELO DE LA CULTURA LABORAL MIGRANTE}

Si una especificación de un modelo quiere decir establecer un orden de los factores revisados en la literatura especializada, entonces una complejización refiere a las diversas relaciones entre estos factores y sus correlaciones supuestas (véase Figura 1).

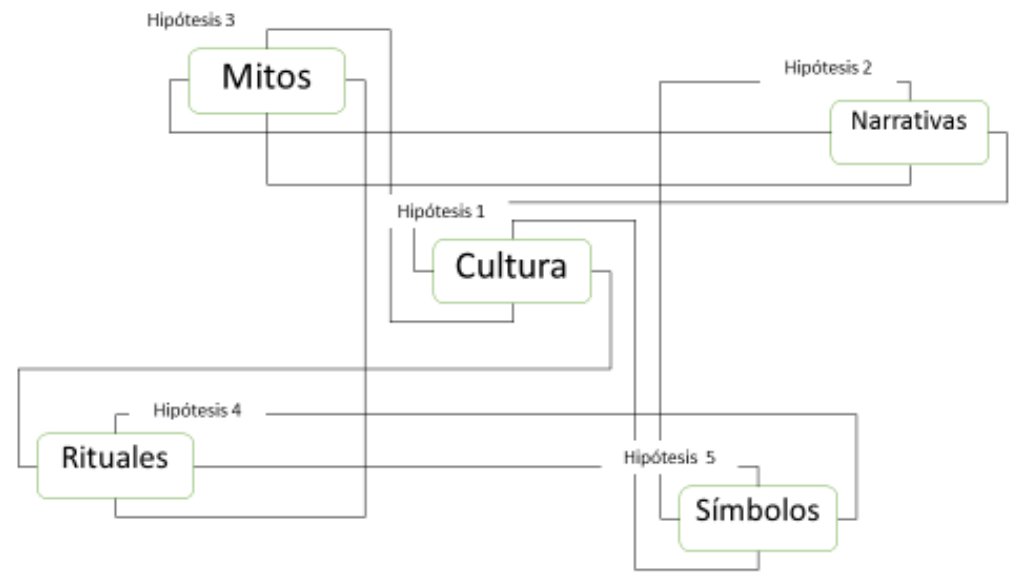

Figura 1. Modelo de la cultura laboral migrante

Fuente: Elaboración propia

La complejización, para fines didácticos, podemos representarla en un modelo en el que están interrelacionados los factores seleccionados. Precisamente, son sus asociaciones las que representan la complejidad de su estudio, no sólo porque cualquier factor pueden incidir y ser influido por cualquier otro factor sino, porque éstos cuatro factores -narrativas, mitos, rituales y simbolismos- convergen en la cultura laboral de los flujos migratorios.

Esto es así al momento en que se inicia la travesía hacia el país receptor, la estancia en el mercado local y el retorno al lugar de origen.

En efecto, el modelo de cultura laboral para el estudio de los flujos migratorios no sólo explica la interrelación entre éstos con culturas oriundas sino, además detalla las relaciones en las fases de travesía, estancia y retorno.

En la travesía, los flujos migratorios portan una serie de valores y normas heredadas de su lugar de origen que se vinculó con la cultura del lugar al que aspiran llegar a través de información difundida en los medios de comunicación, o bien, a través de los discursos de ex migrantes o sus familiares. 
En el caso de la estancia es evidente que existe una interrelación en el trabajo. Las diferencias prevalecientes entre migrantes y oriundos no sólo refieren a la asimilación y adaptación de los trabajadores migrantes, sino a su selección para tareas más específicas o complejas.

En cuanto al retorno de los migrantes, éstos siguen relacionándose con la cultura laboral oriunda a través de símbolos de calidad en los procesos, transferencia de conocimientos o distribución de tareas y recompensas. De hecho, el sentido de responsabilidad es resultado de la interrelación entre los flujos migratorios y las culturas oriundas.

Por consiguiente, el modelo complejiza no sólo la fase de estancia sino, además ofrece la explicación de las diferencias entre migrantes y oriundos en las fases de travesía y retorno, así como una explicación de sus procesos de aculturación, multiculturalismo, interculturalismo y transculturalismo a través de los discursos, narrativas, rituales, simbolismos y mitos del clima de tareas, apoyos e innovaciones.

\section{CONSIDERACIONES FINALES}

El aporte del presente trabajo al estado del conocimiento radica en la complejización de un modelo. Dicho de otro modo, el aporte estriba en el establecimiento de interrelaciones entre los factores esgrimidos en el marco teórico, conceptual y empírico.

No obstante que el modelo explica diversas relaciones, fases y dimensiones, es menester complejizarlo aún más ya que, la selección de la información se limitó a repositorios nacionales y la técnica de análisis de los contenidos fue preliminar a una búsqueda y análisis más avanzado como la minería de textos.

Respecto a los estudios de Carreón et al., (2017) y García, Carreón y Hernández (2017) en el que la identidad es factor esencial para explicar la incidencia de las políticas públicas en la salud ocupacional de los migrantes, el presente trabajo advierte que la identidad puede ser un factor común en la travesía, estancia y retorno, así como en las dimensiones de aculturación, multiculturalismo, interculturalismo y transculturalismo, pero ésta al interactuar con otros factores como las narrativas, mitos, rituales y simbolizaciones complejizan más la problemática y acentúan las diferencias entre migrantes y oriundos. 
Por lo tanto, es recomendable llevar a cabo un estudio sobre la línea de investigación de la identidad reflejada en narrativas, discursos, rituales, simbolizaciones y mitos.

Tal empresa supondrá un revisión y análisis más exhaustivo y diferencial entre los tipos de migrantes y oriundos, así como de las oportunidades del mercado laboral y las capacidades de los actores políticos, sociales y económicos. 


\section{REFERENCIAS}

Carreón, J., Hernández, J. y García, C. (2015). Identidad migratoria en el establecimiento de agenda. Diálogos de Derecho y política, 16 (7), 69-87

Carreón, J., Hernández, J., Bustos, J. M. y García, C. (2017). Políticas de fomento empresarial y sus efectos sobre las percepciones de riego en caficultores de Xilitla, San Luis Potosí, centro de México. Poiesis, 32, 33-51

Carreón, J., Morales, M. L., Rivera, B. L., García, C. y Hernández, J. (2014). Emprendedurismo migrante y comerciante: Estado del conocimiento. Tlatemoani, 15, 158-187

Carreón, j., Pérez, M. I., Valdés, O., Sandoval, F. R., Quintero, M. L. y García, C. (2016). La migración de talentos de México hacia Estados Unidos y La Unión Europea: Especificación de un modelo desde la minería de datos. Fermentum, 77 (26), 179-187

García, C., Carreón, J. y Hernández, J. (2014). Contraste de un modelo del sentido de pertenencia, categorización social, representaciones sociales e identidad laboral en migrantes. Revista Colombiana de Ciencias Sociales, 5 (2), 308-329

García, C., Carreón, J. y Hernández, J. (2017). Límites de los modelos de salud ocupacional. Estudio de la adhesión al tratamiento del asma en trabajadores migrantes adultos mayores del Estado de México. Visión Gerencial, 16 (1), 103-118

García, C., Carreón, J., Hernández, J., Aguilar, J. A. y Rosas, F. J. (2015). Modelo de los determinantes psicosociales de la identidad laboral y la vivienda en ex migrantes de Xilitla, San Luis Potosí (centro de México). Revista Internacional de Investigación en Ciencias Sociales, $11(1), 55-69$

García, C., Montero, M., Bustos, J. M., Carreón, J. y Hernández, J. (2013). La inseguridad migratoria en los medios impresos de la Ciudad de México. Reflexiones, 92 (1), 159-173 